\title{
Efeito do lodo de esgoto em propriedades físicas de um \\ Latossolo Vermelho eutroférrico
}

\section{Effect of sewage sludge on soil physical properties in a Clayey Oxisol}

\author{
Graziela Moraes de C. Barbosa ${ }^{1}$; João Tavares Filho²*; Inês C. de B. Fonseca ${ }^{2}$
}

\section{Resumo}

Estudos com lodo de esgoto, subproduto gerado nas estações de tratamento de esgotos urbanos indicam que este material é rico em matéria orgânica e outros elementos e atua como condicionador do solo, melhorando as propriedades físicas e, portanto, a estrutura dos mesmos. O objetivo deste trabalho foi avaliar algumas propriedades físicas em Latossolo Vermelho eutroférrico que recebeu aplicação de $12 \mathrm{t} \mathrm{ha}^{-1}$ (peso seco) lodo de esgoto caleado durante dois anos. A resistência à penetração do solo foi determinada utilizando-se o penetrômetro de Impacto Modelo IAA/Planalsucar - STOLF, a partir da superfície do solo até a profundidade de $0,50 \mathrm{~m}$, e foram coletadas amostras não deformadas para as análises de densidade e porosidade total do solo. Os resultados demonstraram que a dose de $12 \mathrm{t} \mathrm{ha}^{-1}$ $\mathrm{ano}^{-1}$ de lodo caleado diminuiu a resistência do solo à penetração e a densidade do solo, aumentando a porosidade total do solo.

Palavras-chave: Compactação, atributos físicos, biossólidos

\begin{abstract}
Studies on sewage sludge, a by-product generated in urban sewage treatment shows that the sludge contains several nutrients, is rich in organic matter, and acts as a soil conditioner, thus improving soil structure. The objective of this study was to assess the physical properties in a Clayey Oxisol (Eutrophic Red Latosol) that received $12 \mathrm{t} \mathrm{ha}^{-1}$ (dry weight) of limewashed sewage sludge for two years. Resistance to soil penetration was determined by using the impact penetrometer Model IAA/Planalsucar - STOLF, from topsoil to $0.50 \mathrm{~m}$ depth. Non-deformed samples were collected for the physical analyses of soil density and porosity. Results showed that $12 \mathrm{t} \mathrm{ha}^{-1}$ year $^{-1}$ of limewashed sludge decreased soil resistance to penetration and soil density, thus increasing total soil porosity.
\end{abstract}

Key words: Compaction, physical attributes, Biosolids

${ }^{1}$ Pesquisadora do Instituto Agronômico do Paraná (IAPAR), Área de Solos.Rod. Celso Garcia Cid, Londrina (PR). Fone (43) 33762161.

2 Professores do Depto. de Agronomia, Universidade Estadual de Londrina, C.P. 6001, CEP 86.051-990, Londrina, PR. Fone (43) 3371-4777; e-mail: tavares@uel.br

* Autor para correspondência 
Estudos com lodo de esgoto, subproduto gerado nas estações de tratamento de esgotos urbanos indicam que o mesmo é rico em matéria orgânica e outros elementos e atua como condicionador do solo e, portanto, melhora a estrutura deste.

Um dos principais efeitos da matéria orgânica nos atributos físicos do solo está associado ao aumento da agregação do solo (BARBOSA; TAVARES FILHO; FONSECA, 2002; JORGE; CAMARGO; VALADARES, 1991), à redução da densidade do solo (BARBOSA; TAVARES FILHO; FONSECA, 2002; MELO; MARQUES, 2000) e ao aumento da porosidade total do solo (ASKAR; MAREI; ELZAHER, 1994; PAGLIAI et al., 1981; ORTEGA; NOGALES; DELGADO, 1981). Segundo Rezende (2003), solos com teores mais elevados de matéria orgânica apresentam densidades menores, conseqüentemente estes possuem maior capacidade de retenção de água (SALTON; MIELNICZUK, 1995). Alguns autores relatam que o aumento da matéria orgânica e a redução da densidade do solo deve-se, principalmente, aos cátions presentes no lodo $\left(\mathrm{Ca}^{2+}\right.$ e $\left.\mathrm{Al}^{3+}\right)$, que promovem a agregação das partículas do solo e determinam aumento no volume do mesmo (BARBOSA; TAVARES FILHO; FONSECA, 2002; MELO; MARQUES, 2000; FIEST; ANDREOLI; MACHADO, 1998; JORGE; CAMARGO; VALADARES, 1991).

A resistência do solo à penetração também é influenciada pela densidade e umidade do solo, e pode ser afetada pelas práticas de preparo e manejo do solo (WANTANABE et al., 2002; BORGES et al., 1999). Autores que utilizaram o lodo de esgoto concluíram que a resistência do solo à penetração diminui em função do aumento da porosidade e agregação do solo (AGGELIDES; LONDRA, 2000), melhorando o desenvolvimento de raízes (SOPPER, 1993; BOTTEGA; NASCIMENTO, 1999) e proporcionando maiores produtividades. Nessa linha, fazem-se necessárias pesquisas mais aprofundadas em solos tropicais que receberam doses de lodo de esgoto.
Dessa forma, o objetivo deste trabalho foi de avaliar algumas propriedades físicas em Latossolo Vermelho eutroférrico que recebeu aplicação de 12 t ha ${ }^{-1}$ (peso seco) de lodo de esgoto caleado durante dois anos.

O trabalho foi realizado em um Latossolo Vermelho eutroférrico (teor de argila variando de 760 a $820 \mathrm{~g} \mathrm{~kg}^{-1}$ entre $0-0,40 \mathrm{~m}$ ), localizado em Londrina (PR), coordenadas geográficas $23^{\circ} 23^{\prime}$ de latitude $\mathrm{S}$ e $51^{\circ} 11^{\prime}$ de longitude $\mathrm{W}$, altitude média $566 \mathrm{~m}$ e clima subtropical úmido, segundo classificação de Köppen, do tipo Cfa.

O delineamento experimental utilizado foi de blocos ao acaso com 3 tratamentos e 3 repetições, totalizando 9 parcelas experimentais $\left(240 \mathrm{~m}^{2}\right.$ cada parcela). Os seguintes tratamentos foram testados: T1 - testemunha; T2 - 12 t ha $^{-1}$ ano $^{-1}$ de lodo caleado (uma aplicação anual); T3 - $12 \mathrm{t} \mathrm{ha}^{-1} \mathrm{ano}^{-1}$ de lodo caleado (dividido em duas aplicações: antes da cultura de verão e antes da cultura de inverno).

O lodo utilizado foi digerido anaerobicamente, produzido em estação do tipo Reator Anaeróbico de Lodo Fluidizado - RALF, e tratado pela cal (dolomítica) na concentração de $50 \%$ do peso seco de lodo (denominado lodo caleado após este tratamento), com umidade média de 60\%. A Matéria Orgânica Total encontrada no lodo foi de $362,0 \mathrm{~g} \mathrm{~kg}^{-1}$.

Após o preparo inicial do solo e aplicação da complementação mineral para a cultura do milho, o solo foi gradeado $(0-20 \mathrm{~cm})$ e, aplicou-se manualmente o lodo de esgoto nas doses indicadas pelos tratamentos. As doses foram aplicadas anualmente durante 2 anos consecutivos. Após cada aplicação do lodo de esgoto caleado (início do verão e início do inverno), efetuou-se uma segunda gradagem para incorporação do mesmo. Durante 2 anos procedeu-se como indicado acima e foram implantadas as culturas de aveia e milho nas safras de inverno e verão, respectivamente. Após este período, cessou-se a aplicação de lodo de esgoto e avaliou-se a resistência do solo à penetração. 
A resistência do solo à penetração foi determinada utilizando-se o penetrômetro de Impacto Modelo IAA/ Planalsucar - STOLF, a partir da superfície do solo até a profundidade de $0,50 \mathrm{~m}$, segundo a metodologia descrita em Stolf (1991). Foram coletadas amostras não deformadas para as análises de densidade e porosidade total do solo, segundo metodologia da Empresa Brasileira de Pesquisa Agropecuária EMBRAPA (1997).

Os dados obtidos foram avaliados estatisticamente por meio da análise de variância e teste $\mathrm{t}$ de Student para contrastes ortogonais.
Os resultados de resistência do solo à penetração em Latossolo Vermelho eutroférrico são apresentados no Tabela 1. Observa-se que, ao comparar a testemunha com os tratamentos que receberam o lodo de esgoto caleado (T1 vs $\mathrm{T} 2+\mathrm{T} 3$ ), a resistência do solo à penetração foi significativamente menor na profundidade de $0,20 \mathrm{~m}$ onde se aplicou o lodo, mas na comparação dos tratamentos que receberam lodo (T2 vs T3) entre si, não foi possível verificar, estatisticamente, diferença em nenhuma profundidade.

Tabela 1. Resistência do solo à penetração com umidade entre $0,30 \mathrm{a} 0,35 \mathrm{~m}^{3} \mathrm{~m}^{-3} \mathrm{em}$ um

\begin{tabular}{cccccc}
\hline Tratamentos & \multicolumn{5}{c}{ Profundidade (m) } \\
\cline { 2 - 5 } & 0,10 & 0,20 & 0,30 & 0,40 & 0,50 \\
\hline & 2,83 & 3,91 & 3,40 & 2,82 & 2,86 \\
T1 ${ }^{(1)}$ & 2,43 & 2,84 & 3,02 & 2,56 & 2,85 \\
T2 & 2,72 & 3,00 & 3,28 & 2,88 & 3,06 \\
\hline T3 & $0,554^{(2)}$ & 0,014 & 0,059 & 0,384 & 0,797 \\
T1 vs (T2 +T3) & 0,564 & 0,717 & 0,844 & 0,937 & 0,630 \\
T2 vs T3 & 39,41 & 28,28 & 15,84 & 25,45 & 30,72 \\
\hline CV\% & & &
\end{tabular}

(1) $\mathrm{T} 1=$ testemunha; $\mathrm{T} 2=12 \mathrm{t} \mathrm{ha}^{-1} \mathrm{ano}^{-1}$ de lodo caleado (uma aplicação anual); $\mathrm{T} 3=12 \mathrm{tha}^{-1} \mathrm{ano}^{-1}$ de lodo caleado (dividido em duas aplicações anuais).

(2) p-valor do teste t para contrastes ortogonais;

Contraste $\mathrm{T} 1$ vs $(\mathrm{T} 2+\mathrm{T} 3)$ = comparação de sem lodo com lodo;

Contraste T2 vs T3 = comparação de 1 aplicação com 2 aplicações de lodo.

Souza et al. (2005) trabalharam com doses de lodo de esgoto de até $50 \mathrm{t} \mathrm{ha}^{-1}$, incorporado na camada de 0-0,10 m em Latossolo Vermelho e verificaram que a aplicação deste resíduo não influiu sobre a resistência do solo à penetração. Resultados semelhantes foram encontrados por Smith, Johnston e Lorentz (1997).
Em relação à densidade e porosidade total do solo, os resultados (Tabela 2) demonstraram que na comparação da testemunha com os tratamentos que receberam o lodo (T1 vs T2+T3), houve diminuição dos valores de densidade do solo e aumento na porosidade total, o mesmo não ocorrendo quando comparado somente os dois tratamentos com lodo (T2 vs T3). 
Tabela 2. Efeito da aplicação do lodo de esgoto sobre a densidade do solo (Ds) e porosidade

\begin{tabular}{ccc}
\hline Tratamentos & $\begin{array}{c}\text { Densidade } \\
\left(\mathrm{kg} \mathrm{dm}^{-3}\right)\end{array}$ & $\begin{array}{c}\text { Porosidade total } \\
\left(\mathrm{m}^{3} \mathrm{~m}^{-3}\right)\end{array}$ \\
\hline T1 & 1,32 & 0,49 \\
$\mathrm{~T} 2$ & 1,25 & 0,52 \\
$\mathrm{~T} 3$ & 1,25 & 0,52 \\
$\mathrm{~T} 1$ vs (T2 +T3) & $0,051^{(2)}$ & 0,054 \\
T2 vs T3 & 0,908 & 0,972 \\
CV\% & 6,36 & 7,56 \\
\hline
\end{tabular}

(1) $\mathrm{T} 1$ = testemunha; $\mathrm{T} 2=12 \mathrm{t} \mathrm{ha}^{-1}$ ano $^{-1}$ de lodo caleado (uma aplicação anual); $\mathrm{T} 3=12 \mathrm{t} \mathrm{ha}^{-1}$ ano $^{-1}$ de lodo caleado (dividido em duas aplicações anuais).

(2) p-valor do teste t para contrastes ortogonais.

Como a incorporação do lodo de esgoto foi realizada com a grade na camada de 0,0 a $0,20 \mathrm{~m}$, antes do plantio do milho, esse efeito do revolvimento do solo da camada superficial pode ter influenciado nos valores encontrados na resistência do solo à penetração, na redução da densidade do solo e no aumento da porosidade total. Aggelides e Londra (2000) também verificaram menor resistência do solo à penetração utilizando $78 \mathrm{t} \mathrm{ha}^{-1} \mathrm{ano}^{-1} \mathrm{com}$ uma mistura de $62 \%$ de lixo doméstico, $21 \%$ lodo de esgoto e $17 \%$ de serragem na profundidade de $0,15 \mathrm{~m}$ em solo argiloso.

Alguns autores verificaram que a redução da densidade do solo e aumento da porosidade total indica a melhor estrutura do solo em função da aplicação do lodo de esgoto caleado apresentando melhor desenvolvimento das raízes (BOTTEGA; NASCIMENTO, 1999; SOPPER, 1993), pois o aumento da matéria orgânica no solo reduz a plasticidade e aumenta a capacidade de retenção de água (CASTRO FILHO; MUZILLI; PODANOSCHI, 1998; BAYER; MIELNIZUCK, 1997), melhora a aeração e diminui a resistência do solo à penetração de raízes (LETEY, 1985).

De acordo com os resultados obtidos concluiu-se que a dose de $12 \mathrm{t} \mathrm{ha}^{-1}$ ano $^{-1}$ de lodo caleado diminuiu a resistência do solo à penetração, a densidade do solo e aumentou na porosidade total.

\section{Referências}

AGGELIDES, S. M.; LONDRA, P. A. Effects of compost produced from town waster and sewage sludge on the physical properties of a loamy and clay soil. Bioresource Technology, Essex, v.71, p.253-259, 2000.

ASKAR, F. A.; MAREI, S.; ELZAHER, H. Sewage sludge as natural conditioner for newlyreclaimed soils. Egyptain Journal of Soil Science, Cairo, v.34, n.1, p.67-77, 1994.

BAYER, C.; MIELNICZUK, J. Características químicas do solo afetadas por métodos de preparo e sistemas de cultura. Revista Brasileira de Ciência do Solo, Campinas, v.21, p.105-112, 1997.

BARBOSA, G. M.C.; TAVARESFILHO, J.; FONSECA, I.C.B. Avaliações de propriedades físicas de um latossolo vermelho eutroférrico tratado com lodo de esgoto por dois anos consecutivos. Sanare, Curitiba, v.17, n.17, p.94-101, 2002.

BORGES, E. N.; LOMBARDINETO, F. L.; CORREA, G. F.; BORGES, E. V. S. Alterações físicas introduzidas por diferentes níveis de compactação em Latossolo VermelhoEscuro textura média. Pesquisa Agropecuária. Brasileira, Brasília, v.34, n.9,p.1663-1667, 1999.

BOTTEGA, J. C.; NASCIMENTO, E. B. Utilização do lodo de esgoto em pequenas propriedades agrícolas. In: ANDREOLI, C. V.; LARA, A. I.; FERNANDES, F. (Org.). Reciclagem de biossólidos: transformando problemas em soluções. Curitiba: SANEPAR/FINEP, 1999.

CASTRO FILHO, C.; MUZILLI, O.; PODANOSCHI, A. L. Estabilidade dos agregados e sua relação com o teor de carbono orgânico num Latossolo Roxo distrófico, em função de sistemas de plantio, rotações de culturas e métodos de preparo de amostras. Revista Brasileira de Ciência do Solo, Campinas, v.22, p.527-538, 1998. 
EMPRESA BRASILEIRA DE PESQUISA AGROPECUÁRIA - EMBRAPA. Manual de métodos de análise de solo. 2.ed. Rio de Janeiro: EMBRAPA, 1997.

FIEST, L. C.; ANDREOLI, C. V.; MACHADO, M. A. M. Efeitos da aplicação do lodo de esgoto nas propriedades físicas do solo. Sanare, Curitiba, v.9, n.9, p.48-57, 1998.

JORGE, J. A.; CAMARGO, O. A.; VALADARES, J. M. A. S. Condições físicas de um latossolo vermelho-escuro 4 anos após a aplicação de lodo de esgoto e calcário. Revista Brasileira de Ciência do Solo, Campinas, v.15, p.237-240, 1991.

LETEY, J. Relationship between soil physical properties and crop production. Advances in Soil Sciences, New York, v.1, p.277-294, 1985.

MELO, W. J.; MARQUES, M. O. Potencial do lodo de esgoto como fonte de nutrientes para as plantas. In: BETTIOL, W.; CAMARGO, O. A., (Ed.). Impacto ambiental do uso agrícola do lodo de esgoto. Jaguariúna: EMBRAPA Meio Ambiente, 2000. p.109-141.

ORTEGA, E.; NOGALES, R. \& DELGADO,M. Modification em la prosidad de um suelo por lá adición de um compost de basura urbana. Anales de Edafologia $Y$ Agrobiologia, Madrid, v.15, p.1735-1747, 1981.

PAGLIAI, M.; GUIDI, G.; LA MARCA, M.; GIACHETTI, M.; LUCAMANTE, G. Effects of sewage sludge and compost on soil porosity and agregation. Journal Environmental Qualit., Madison, v.10, p.556-561, 1981.
REZENDE, M. O. O. O ciclo do carbono na natureza e a qualidade do solo no ponto de vista químico. $A$ importância da matéria orgânica do solo no ciclo do carbono. 2003.p.96.

SALTON, J. C.; MIELNICZUK, R. Relações entre sistemas de preparo, temperatura e umidade de um Podzólico Vermelho Escuro de Eldorado do Sul - RS. Revista Brasileira de Ciência do Solo, Campinas, v.19, p.213-224, 1995.

SMITH, C. W.; JOHNSTON, M. A.; LORENTZ, S. The effect of soil compaction and soil physical properties on the mechanical resistance of South African forestry soils. Geoderma, Amsterdam, n.8, p.93-111, 1997.

SOPPER, W.E. Municipal sludge use in land reclamation. New York: Lewis, 1993.

SOUZA, Z. M.; BEUTLER, A. N.; MELO, V. P.; MELO, W. J. Estabilidade de agregados e resistência à penetração em Latossolos adubados por cinco anos com biossólido. Revista Brasileira de Ciência do Solo, Campinas, v.29, p.117-123, 2005.

STOLF, R. Teoria e teste experimental de fórmulas de transformação dos dados de penetrômetro de impacto em resistência do solo. Revista Brasileira de Ciência do Solo, Campinas, v.15, p.229-235, 1991.

WATANABE, S. H.; TORMENA, S. A.; ARAUJO, M. A.; VIDIGAL FILHO, P. S.; PINTRO, J. C.; COSTA, A. C. S.; MUNIZ, A. S. Propriedades físicas de um Latossolo Vermelho distrófico influenciadas por sistemas de preparo do solo utilizados para implantação da cultura de mandioca. Acta Scientiarun, Maringá, v.24, p.1255-1264, 2002. 